\title{
Posthumanism: \\ A Navigation Aid for Educators
}

\author{
Siân Bayne (University of Edinburgh)
}

\section{Introduction}

Posthumanism is broadly concerned with the questioning of human exceptionalism and the foundational role of 'humanity' as it has been constructed in modernity. Rejecting any clarity of distinction between 'nature' and 'culture', it works against dualism and the binaries we have tended to draw on to define what it means to be human. In this sense it is - in its critical forms - radically at odds with the often reductive transhumanisms critiqued in the introduction to this issue which assume technological 'enhancement' of the human body can take place without a fundamental re-thinking of human subjectivity itself.

While the implications of critical posthumanism for education are significant, it can present a difficult terrain for scholars new to this area of thought - its literatures are wide, cross-disciplinary, complex and in some instances (the relationship between posthumanism and transhumanism being one example) contradictory with itself. This can make it problematic for scholars and practitioners, in education and other areas, who are trying to unpick its implications for applied fields.

This article looks back at some of the genealogies of posthumanism, offering what is hopefully an accessible way into understanding this complex area of thought for the growing numbers of scholars wishing to apply it to educational concerns. In doing so, it structures the existing, substantial literature on posthumanism into three broad categories - critical posthumanism, technological posthumanism and ecological posthumanism - briefly indicating how each of these might hold different kinds of explanatory power for educational practice and research.

Posthumanism is perhaps best understood as "a philosophical movement critical of the foundational assumptions of classical humanism that structure so much of life as we know, live, and understand it" (Letts and Sandlin, 2013). Its most-quoted early naming was in 1977 when Ihab Hassan declared that:

"We need to understand that five hundred years of humanism may be coming to an end, as humanism transforms itself into something that we must helplessly call posthumanism“ (Hassan, 1977, p. 843).

In fact, the various critiques of humanism which emerged around the middle of the $20^{\text {th }}$ century meant that by the 1990 s, when posthumanism was gaining volition in many disciplines, "there was already a sizeable literature explaining why 'the human' must be compulsively draped in scare-quotes" (Castree and Nash, 2004). But what is the version of humanism that is being challenged here? It is not, in general, the secular humanism offered by 'progressive' rationalism as an alternative to conventional religion, but rather the liberal humanism - challenged as deeply reactionary by $20^{\text {th }}$ century continental philosophy - which claims:

"that the figure of 'Man' (sic) naturally stands at the centre of things; is entirely distinct from animals, machines, and other nonhuman entities; is absolutely known and knowable to 'himself'; is the origin of meaning and history; and shares with all other human beings a universal essence" (Badmington, 2004, p. 1345).

It is this strand of humanism in its liberal form - with its roots in the philosophy of Descartes, Locke, Rousseau, Kant, Leibniz and others - which is challenged and deconstructed by critical forms of posthumanism. Much of this thinking is concerned with the deconstruction of the oppositional terms which function to define and contain what 'counts' as human (human/animal, nature/culture, subject/object, self/other, mind/body). As Braidotti suggests, it is time now to think beyond rationality, self-regulation and the definition of self in opposition to 'other', because “humanism's restricted notion of what counts as the human is one of the keys to understand how we got to a post-human turn at all“" (Braidotti, 2013).

To simplify, posthumanism involves us in making an ontological shift from understanding 'the human' as an individuated entity separate from and observant of the world and its (human and non-human) inhabitants, to one which is inextricably connected to the world and only conceivable as emergent with and through it.

While much posthumanism is concerned with what comes after philosophical humanism, it has not until relatively recently been apocalyptic. Though a trope in the science fiction imaginary for decades, the tendency to view the posthuman as an historical moment - an 'end point' for humanity - has been until recently less of a focus than the 'end point' of a particular kind of human 
subject. As Hayles succinctly pointed out in 1999, the posthuman only signals "the end of a certain conception of the human", one applying to "that fraction of humanity who had the wealth, power, and leisure to conceptualize themselves as autonomous beings exercising their will through individual agency and choice“" (1999, p. 286).

In recent years, however, climate crisis and the accelerated extinction of species have brought into sharp focus the need for posthumanist thought to address the material effects of the human plundering of the ecosystems which maintain life. Posthumanism, it is argued by some, can no longer focus on subjectivity alone, but must rather engage with the possibility of extinction (Colebrook, 2014). Clearly, the challenges such a view poses to the project of education are significant, and are returned to in a later section.

\section{Posthumanism in education}

As Pedersen (2015) reminds us, education is often viewed as the "humanist project par excellence", seen as a "a key component of compulsory becoming-human...connected to a general idea of education as something inherently 'good', that can somehow make us become better human beings" (no page). Usher and Edwards (Usher and Edwards, 1994) perhaps best summarised the problematic position education finds itself in once its humanistic foundations have been troubled:

"The very rationale of the educational process and the role of the educator is founded on the humanist idea of a certain kind of subject who has the inherent potential to become self-motivated and selfdirecting, a rational subject capable of exercising individual agency. The task of education has therefore been understood as one of 'bringing out', of helping to realise this potential, so that subjects become fully autonomous and capable of exercising their individual and intentional agency“ (p. 24).

If, via posthumanism, we accept that it is oversimplistic to think in terms of education as the liberation or 'bringing out' of essential human potential, we are left with the task of re-thinking what education is for. Perhaps not surprisingly, given the centrality of this assumed humanism to much educational research, practice and policy, educational thought has been relatively slow to engage with this challenge. However, recent thinkers have done much to advance the debate: in particular writing and edited collections from Pedersen (2013; 2015), Biesta (1998; 2011), Snaza and Weaver (2015), Knox (2016), Taylor and Hughes (2016) and Lather and St. Pierre (2013) have been highly influential in carving out the territory and extending thinking across the various fields of educational practice and research.

The intention of this short article is not to provide a comprehensive review of this and other current work, but rather to try to make the field navigable by mapping the genealogies of posthumanism into three broad categories - critical posthumanism, technological posthumanism and ecological posthumanism. The categories of course overlap, however each holds a slightly different kind of explanatory power for educational practice and research, providing a loose structure by which we might understand it.

\section{Critical posthumanism}

The most important genealogy of critical posthumanism goes back to the mid- $20^{\text {th }}$ century and the questioning in philosophy and theory of the basic tenets of humanism, and of how 'Man' came to be conceived and constructed:

"The revolutionary Enlightenment narratives that challenged an oppressive feudal order and reenvisioned 'man' as rational, autonomous, unique, and free have been in turn challenged and deconstructed. The emancipatory impulse of liberal humanism has come to be understood as being unwittingly complicit in colonialist, patriarchal, and capitalist structures“ (Simon, 2003).

Where the assumption of a 'core humanity' and a shared human essence based in reason and autonomy still "continues to enjoy the status of 'common sense' in contemporary Western Culture" (Badmington, 2000), this perspective was no longer tenable in critical thought post1968, after poststructuralism had worked-over all the fundamental tenets of enlightenment humanism: Foucault had proclaimed the 'death of Man', 'human nature' had been declared a social and discursive construct, feminist poststructuralism had critiqued and taken apart the maleness of 'Man' and post-colonial theory had emphasised 'his' oppressive whiteness.

After this, it became difficult in critical thought to see the human subject as existing outside history or outside political, discursive and material practice: instead it became necessary to see 'the human' as defined by the workings of power. Feminist and postcolonial readings provide rich insight into the ways in which who or what counts as fully 'human' is determined by those with the power to define it. Feminism drew - and continues to draw - attention to the ways in which the human subject has been consistently identified with the human male; postcolonialism revealed how throughout the $20^{\text {th }}$ century various figures were "nominated to fill the slot" of the 'nonhuman' - ,"the Jew, the slave, the barbarian, the foreigner" (Braun, 2004, p. 1353). And in educational philosophy Biesta drew our attention to how, in viewing education as a means to an end (the end being the child's entrance into the "domain of real intersubjectivity"), we construct the child herself as "not yet a real human being" (Biesta, 1998, p. 11). As the theorists so briefly referred to here emphasise in different ways, the question of who gets 
to define what counts as human is crucial. "Who", as Biesta asks, "designs the entrance exam for humanity?" (ibid.).

If it is no longer possible to define humanity as an essence, as a neutral, universally shared property which exists independently of the social, the material and the discursive - we are left with what Braun (2004, p. 1352) has called a "devastating absence" where 'Man' once existed. It is this absence which, in various ways, posthumanism attempts to navigate. However in many of its forms it steps back from post-structuralist antihumanism by seeking to understand what it is productive to retain of humanism in our current era. Braidotti (2013), for example, suggests that we do not need to abandon the notion of human subjectivity but rather to re-think it in radical posthumanist terms. She proposes a shift from what she calls "unitary to nomadic subjectivity" as a strategy for rejecting both humanist individualism, and the relativism of anti-humanism (p. 49).

Nomadic subjectivity enables us to take account of "the inter-connection between self and others...by removing the obstacle of self-centred individualism“ (p. 50). It enables us to retain enough of the humanist subject to take an ethical and socially just position on the world, without ascribing to the oppressive and problematic principles of 'high humanism'. Braidotti's mode of posthumanism aligns with the 'new materialist' thought which has been influential in the humanities and social sciences, emphasising as it does the agency of non-human matter and the need to revisit questions of human subjectivity in light of ecological crisis, contemporary geopolitics and technological shift (for example Dolphijn and van der Tuin 2012).

Davies (2008), in also considering the relationship of posthumanism to humanism, paints a picture of the latter as battered but still surviving in contemporary posthumanist thought. Posthumanism, for him, serves the "unmistakably humanist....ends of understanding and emancipation" (p. 140): this is a "chastened humanism...shorn of its swagger and selfrighteousness...but a kind of humanism nonetheless“ (p. 141). After all, it is the building blocks of post- $18^{\text {th }}$ century science, he argues, ('scepticism, observation, hypothesis and experiment') which have brought us to a position of conceiving posthumanism at all.

While Davies emphasises the dependence of posthumanism on humanism, other writers focus on the idea that we have always been posthuman. If current posthumanist thought tends to focus on the blurriness of the boundary between the human and the non-human and the mutually-embeddedness of the social and the material, it seems to presuppose that "once upon a time things were not this way, that at an earlier moment the boundaries really did exist and the human was purely, simply, 'itself'“ (Braun, 2004). Thus Wolfe (2010) is able to see posthumanism as coming both before and after humanism: "before in the sense that it names the embeddedness of the human being in not just its biological but also its technological world... and after in the sense that posthumanism names a historical moment in which the decentring of the human by its imbrication in technical, medical, informatic, and economic networks is increasingly impossible to ignore" (p. $\mathrm{xv})$.

This inextricable involvement of the human in its networks - technical and informatic - offers a nice link to the cluster of literatures I have grouped under term of 'technological posthumanism'.

\section{Technological posthumanism}

For education, the implications of seeing the human as inseparable from the networks or ecologies within which it is assembled are profound, in that they challenge the very possibility of the rational cognition and individual agency which we have seen education as existing to nurture. Hayles (2006) uses the notion of the 'cognisphere' as a way of re-thinking the humanistic educational privileging of agency and cognition. Seeing the cognisphere as the huge, global 'pyramid of data flows', of which human awareness can only ever encompass a tiny fraction, she proposes a 'benign' form of posthumanism which is concerned with:

"transforming untrammelled free will into a recognition that agency is always relational and distributed, and correcting an over-emphasis on consciousness to a more accurate view of cognition as embodied throughout human flesh and extended into the social and technological environment" (p. 160-161).

For Rousell (2016), this carries implications for the way we understand the learning environments of schools and universities as emergent and actively co-constituted by human and non-human agents and entities:

"the learning environment is not constructed by humans and for humans to apprehend, but is rather constituted through the complex relations between entities in a collective field of engagement, some of whom may happen to be human“ (p. 145).

Such a view problematises the assumption in much educational practice that the human subject can be seen as separate from the objects of knowledge with which it is concerned. Knowledge in the humanistic view is a question of representing accurately those objects over which we have dominance as autonomous observers. For posthumanism, this separation of subject and object is no longer tenable - the observer is inextricably involved in 
the system which is observed, the human is irrevocably extended into the networks within which it is entangled, and as it is no longer possible to isolate human consciousness from its social and technological environment (Hayles, 2006), it is no longer possible to represent knowledge of this environment from a position of externality. As Edwards puts it, "education has focused on the learning subject as a result of an a priori assumption of a separation of matter from meaning, the object from the subject" (Edwards, 2010, p. 8) - a position which seems increasingly less tenable as datafied societies and 'algorithmic selfhoods' are becoming rapidly normalised (Pasquale, 2015).

Thus for Edwards, drawing on the work of Barad (2007), Latour (1993) and Hacking (1983), the "posthuman condition cannot be one of learning", since the subject 'doing' the learning and the object 'being learned' are no longer readily distinguishable from each other. The outside/inside binary has collapsed alongside that of the subject/object. If posthumanism marks the end of 'learning', the work of education becomes to focus on how 'matters of concern' (Latour, 2004) "arise from the work of specific practices and assemblages of the human and non-human“ (Edwards, 2010, p. 9).

This perspective is particularly useful when considering the implications of digital aspects of contemporary education, as a way of stepping back from the still widely-held assumption that the value of digital technology in education is largely instrumental, with digital technology seen as a 'tool' to be used to make education 'better' (more efficient, more effective, more available). Some of the more social science-informed inflections of posthumanism - in particular, the sociomaterial influences of science and technology studies - have been particularly useful in this regard (summarised in Fenwick, Edwards and Sawchuck, 2011). For example, Introna and Hayes (2011) have written on the way in which plagiarism-detection algorithms in commercial services and sotware (such as Turnitin, routinely used within higher education to attempt to address academic misconduct in student essays and coursework) actively construct certain groups of students as 'cheats'. Knox (2014) has drawn our attention to the ways in which algorithmically-determined 'personalisation' in learning environments is an emergent property of a sociomateriality beyond the control of individual human agency, while Williamson (2018) has extended critique into the biotechnological domain of educational genomics which proposes the 'personalisation' of education through analysis of individual children's genetic profiles (see Gulson and Baker, 2018, for more on the 'biosocial turn' in education).

These approaches, posthumanist in different ways and to different extents trace the specificities of technological artefacts and the performative function of code, data and algorithm, examining them in detail and working with the notion of the indivisibility of 'the technological' and 'the social'. Such machinic fusions are important for the ways in which they bring us to an understanding of our mutual dependence on the non-human, and the inadequacy of 'common-sense' assumptions of human exceptionalism and centrality, or 'anthropocentrism'.

\section{Ecological posthumanism}

'Ecological' posthumanism is a compromise term for clustering a set of ideas that extends across multiple disciplines concerned with post-anthropocentrism or the shifting of 'the human' from the centre of the way in which we conceive of the world, emphasising the vital and productive inextricability of the human from its material and environmental ecologies.

For Braidotti and others writing within what has come to be called the 'new materialism' (for example Barad, 2007, Coole and Frost, 2010, Dolphijn and van der Tuin, 2012), posthumanism contests the idea of the 'human' as a transcendent category and instead emphasises the inseparability of the human from the "dynamic, selforganising structure of life itself", cutting across and reconnecting "previously segregated species, categories and domains" (p. 60). Theory in this area is heavily influenced by the philosophy of Spinoza, Bergson and Deleuze, particularly as played out in the concept of a 'new vitalism' which emphasises becoming over being in the way we think about life and what it means to be 'alive' (for an accessible genealogy of new vitalism see Olma and Koukouzelis, 2007, and also the work of Bennet, who pulls the two vocabularies together under the terminology of 'vital materialism' (Bennett 2010)). Fraser et al. (2005) emphasise the importance of 'radical relationality' to this way of thinking: that the world is composed only and always through the enfolding and mutual constitution of matter and meaning.

This relationality enables us to think against the various - often problematic - category segregations through which we have learned to make sense of the world, in the academic disciplines as well as in the constructs that inform and shape our everyday lives. Some of the most interesting work emerging in the field of education from this area emerges from the field of animal studies and the issue of species segregation: the privileging of the 'human animal' over the 'non-human animal' and how - as educators - we challenge the assumption of 'human exceptionalism' (Weil, 2012).

The homogenising category of 'the animal' has allowed us to build an idea of 'the human' as separate from its animal 'other', justifying a project of human domination over nature which has - in the face of ecological crisis, the mass extinction of species and the socially normalised abuse of non-human animals - proven deeply problematic (Derrida, 2002).

Helena Pedersen and colleagues have written extensively on the challenge of educational speciesism and the possibility of a 'critical animal pedagogy' which 
asks what education might become "when humans are not regarded as the only subjects" (Dinker and Pedersen, 2016). Moving away from understanding animals in terms of their use-value in the classroom may entail working to the idea of the human and animal as mutually entangled, or - as Dinker and Pederson argue - instead developing a pedagogical ethics which simply "leaves the animal alone". In this they draw on MacCormack (2013) who describes the need to develop 'pedagogical grace', "the unthinking of man simultaneous with the leaving be of the nonhuman - teaching ways to unthink the self in order to open up the thought of the world" (p. 13).

Post-anthropocentric thought of course extends across other disciplines and fields beyond those we might describe as 'animal studies', and it is important to emphasise that not all such scholarship would necessarily describe itself as 'posthumanist'. The 'hectic bonds' between people, plants, animals and objects through which a new ontology of the posthuman is formed (Whatmore, 2002) are a core concern within cultural geography and environmental humanities. Each of these engage with the idea that we are living in an age in which humanity's effect on the planet is so profound as to institute a new geological era, termed the 'Anthropocene' (Crutzen, 2002), in which the effects on the planet of human action have generated fundamental and irreversible environmental change.

Some environmental humanists argue that the term 'Anthropocene' - taken from work conducted in the geosciences - unhelpfully re-asserts the notion of "human supremacy" (Crist, 2013, p. 133). Others propose that the terminology and currency of the Anthropocene creates a moment in which the humanities should take a stronger role in pushing forward thought and action on planetary crisis (Castree, 2014). For many in the environmental humanities, this is a moment in which we need to do more than simply improve our 'stewardship' of the planet 'stewardship' itself argued to be a perspective driven by the idea of human exceptionalism and dominance - but rather to make a fundamental shift into a 'different mode of humanity' as we engage with the notion of extinction as both 'thought experiment' and reality (Weisman, 2007, Colebrook, 2014). For many writers in this field, the abandonment of the mode of human dominance over nature is a theoretical shift driven by intense crisis, as human action forges irreversible ecological and planetary change.

The implications of such crisis for how we think about education are immense. A failure to engage with them - to continue to teach as though the world can only be thought from a perspective which places the 'human' at its core - is seen by some as insupportable:

"That after the extinction of human life some alien scientist might discover a schoolhouse or University lecture hall and ascertain therein no fundamental shift in thinking or practice will undoubtedly be perplexing. 'It was as if they carried on as they ever did despite the encroaching horror accelerating towards them.... “' (Wallin, 2017, p. 1107).

\section{Conclusion}

This article has broken down, reduced and ordered a labyrinthine, transdisciplinary body of scholarship into three distinct and very abbreviated categories. In doing so it has necessarily simplified them, and perhaps implied a discreteness between them which does not really exist. However by drawing on the theories and traditions of posthumanism, and connecting these to the broader concerns of post-anthropocentric thought, we provide ourselves with a rich map of the territory to be negotiated as educators and educational researchers, which is addressed in different ways by the editors and contributors to this issue of on_education. We also, perhaps, give ourselves greater permission to experiment. As Whatmore (2002) suggests, the "greatest challenge presented by these more-than-human styles of working is the onus they place on experimentation and, by implication, on taking (and being allowed to take) risks“" (p. 606). In terms of our practice as teachers and researchers, we can see this as an incitement to continue to push at the boundaries of educational possibility, and to do so not within an instrumentalised, commodified understanding of education, but rather one which critically explores what it means - in this moment - to be 'connected'.

\section{References}

Badmington, N. (2000). Posthumanism. Basingstoke: Palgrave.

Badmington, N. (2004). Mapping posthumanism: An exchange. Environment and Planning A, 36, $1344-1351$.

Barad, K. (2007). Meeting the universe halfway. Durham: Duke University Press.

Bennett, J. (2010). Vibrant matter: A political ecology of things. Durham: Duke University Press.

Biesta, G. (1998). Pedagogy without humanism: Foucault and the subject of education. Interchange, 29(1), 1-16.

Biesta, G. (2011). Philosophy, exposure, and children: How to resist the instrumentalisation of philosophy in education. Journal of Philosophy of Education, 45, 305-319.

Braun, B. (2004). Modalities of posthumanism. Environment and Planning A, 36, 1352-1355. 
Calarco, M. (2008). Zoographies: The question of the animal from Heidegger to Derrida. New York, NY: Columbia University Press.

Castree, N. (2014). The anthropocene and the environmental humanities: Extending the conversation. Environmental Humanities, 5, 233-260.

Castree, N. \& Nash, C. (2004). Introduction: Posthumanism in question. Mapping posthumanism: An exchange. Environment and Planning A, 36, 1341-1343.

Colebrook, C. (2014). The Death of the PostHuman: Essays on extinction, volume one. Ann Arbor, MI: Open Humanities Press.

Coole, D. \& Frost, S. (eds.) (2010). New materialisms: ontology, agency, and politics. Durham: Duke University Press.

Crist, E. (2013). The poverty of our nomenclature. Environmental Humanities, 3, 129-46.

Crutzen, P. J. (2002). The 'Anthropocene'. Journal de Physique IV, 12(10), 1-5.

Davies, T. (2008). Humanism. Abingdon: Routledge.

Derrida, J. (2002). The animal that therefore I am (more to follow). Critical Inquiry, 28, 369-418.

Dinker, K. G. \& Pedersen, H. (2016). Critical animal pedagogies: Re-learning our relations with animal others. Lees, H. E. \& Noddings, N. (eds). The Palgrave international handbook of alternative education. London: Palgrave Macmillan.

Dolphijn, R. \& van der Tuin, I. (eds.) (2012). New materialism: Interviews and cartographies. Ann Arbor, MI: Open Humanities Press.

Edwards, R. (2010). The end of lifelong learning: A post-human condition? Studies in the Education of Adults, 42 (1), 5-17.

Fenwick, T., Edwards, R. \& Sawchuck, P. (2011). Emerging approaches to educational research: Tracing the sociomaterial. Abingdon: Routledge.

Fraser, M., Kember, S. \& Lury, C. (2005). Inventive life: Approaches to the New Vitalism. Theory, Culture \& Society, 22(1), $1-14$.

Hacking, I. (1983). Representing and intervening: Introductory topics in the philosophy of natural sciences. Cambridge: Cambridge University Press.

Hassan, I. (1977). Prometheus as performer: Towards a posthumanist culture? The Georgia Review, 314, 830-850.

Hayles, K. N. (1999). How we became posthuman: Virtual bodies in cybernetics, literature and informatics. Chicago, IL: University of Chicago Press.

Hayles, K. N. (2005). My mother was a computer: Digital subjects and literary texts. Chicago, IL: University of Chicago Press.

Hayles, K. N. (2006). Unfinished work: From cyborg to cognisphere. Theory, Culture and Society, 23(7-8), 159-166.

Introna, L. D. and Hayes, N. (2011). On sociomaterial imbrications: What plagiarism detection systems reveal and why it matters. Information and Organization, 21, 107-122.

Gulson, K. N. \& Baker, B. M. (2018). New biological rationalities in education, Discourse: Studies in the Cultural Politics of Education, 39(2), 159-168.

Knox, J. K. (2014). Active algorithms: Sociomaterial spaces in the e-learning and digital cultures MOOC, Campus Virtuales, $3(1), 42-55$.

Knox, J. K. (2016). Posthumanism and the massive open online course. New York, NY: Routledge.

Lather, P. \& St. Pierre, E. (2013). Post-qualitative research. International Journal of Qualitative Studies in Education, 26(6), 629-633.

Latour, B. (1993). We have never been modern. Cambridge, MA: Harvard University Press.

Latour, B. (2004). Why has critique run out of steam? From matters of fact to matters of concern. Critical Inquiry, 30, 225248.

MacCormack, P. (2013). Gracious pedagogy. Journal of Curriculum and Pedagogy, 10(1), 13-17.

Pasquale, F. (2015) The algorithmic self. The Hedgehog Review, 17(1).

Pedersen, H. (2013). Follow the Judas sheep: Materializing post-qualitative methodology in zooethnographic space. International Journal of Qualitative Studies in Education, 26(6), 717-731.

Pedersen, H. (2015). Education and posthumanism. Retrieved from http://criticalposthumanism.net/genealogy/education/

Rousell, D. (2016). Dwelling in the Anthropocene: Reimagining university learning environments in response to social and ecological change. Australian Journal of Environmental Education, 32(2), 137-153.

Simon, B. (2003). Introduction: towards a critique of posthuman futures. Cultural Critique, 53, 1-9.

Snaza, N. \& Weaver, J. (2015). Posthumanism and educational research. New York, NY: Routledge.

Taylor, C. \& Hughes, C. (eds.) (2016). Posthuman research practices in education. London: Palgrave Macmillan.

Wallin, J. (2017). Pedagogy at the brink of the post-anthropocene. Educational Philosophy and Theory, 49(11), $1099-1111$.

Weil, K. (2012). Thinking animals: Why animal studies now? New York, NY: Columbia University Press.

Weisman, A. (2007). The world without us. New York, NY: Picador.

Whatmore, S. (2002). Hybrid geographies: Natures, cultures, spaces. London: Sage. 
Williamson, B. (2018, June 18) Scientists seek genetic data to personalize education. DMLCentral. Retrieved from https://dmlcentral.net/scientists-seek-genetic-data-to-personalize-education/

Wolfe, C. (2010). What is posthumanism? Minneapolis, MN: University of Minnesota Press.

\section{Recommended Citation}

Bayne, S. (2018). Posthumanism: A navigation aid for educators. On Education. Journal for Research and Debate, 1(2). https://doi.org/10.17899/on_ed.2018.2.1

\section{About the Author}

Sian Bayne is Professor of Digital Education and Director of Education for the Edinburgh Futures Institute at The University of Edinburgh. Based in the Centre for Research in Digital Education, her research is currently focused on higher education futures, interdisciplinary approaches to theorising and researching digital education, and digital pedagogy. More information about her work is on her web site at: http://sianbayne.net 